\title{
Impact of Radical Prostatectomy on Urinary Incontinence, Erectile Dysfunction and General Quality of Life
}

\author{
Sarita Mac Cornick ${ }^{1,2 *}$, Silvana Aparecida Alves Corrêa ${ }^{1}$, Márcia Eli Girotti², \\ João Paulo Zambon², Rogério Simonetti Alves², Fernando Gonçalves de Almeida ${ }^{2}$ \\ ${ }^{1}$ Division of Plastic Surgery, Department of Surgery, Universidade Federal de Sao Paulo/Escola Paulista de \\ Medicina (UNIFESP/EPM), Sao Paulo, Brazil \\ ${ }^{2}$ Division of Urology, Department of Surgery, Universidade Federal de São Paulo/Escola Paulista de Medicina \\ (UNIFESP/EPM), São Paulo, Brazil \\ Email: silaac@globo.com
}

Received 18 April 2015; accepted 23 August 2015; published 26 August 2015

Copyright (C) 2015 by authors and Scientific Research Publishing Inc.

This work is licensed under the Creative Commons Attribution International License (CC BY). http://creativecommons.org/licenses/by/4.0/

(c) (i) Open Access

\begin{abstract}
The aims of this study were to evaluate the impact of radical retropubic prostatectomy on patient's quality of life. Patients undergoing radical retropubic prostatectomy were followed for six months after surgery. We used quality of life questionnaires to study specific urinary symptoms and general health. WHOQOL-Bref (World Health Organization for Quality of Life) questionnaire was used to evaluate general health aspects, ICIQ-SF (International Consultation on Incontinence Questionnaire-Short Form), OABq (Overactive Bladder) and IPSS (International Prostatic Symptom Score) to evaluate incontinence and overactive bladder symptoms and Male Sexual Quotient to assess postoperative sexual dysfunctions. The questionnaires were scheduled before surgery, one, three and six months after surgery. Regarding the OAB-q scores, I-PSS and WHOQOL-Bref (physical, psychological, environmental, general, Question 1 and Question 2), symptoms worsened after one month if compared to preoperative symptoms. After six months, the WHOQOL's social domain, the ICIQ-SF and QS-M scores remained worse if compared to preoperative evaluation. The incidence of sexual dysfunctions after six months was 0.83 . In conclusion, urinary incontinence affects patient's quality of life with gradual recovery after six months postoperatively. The social domain was the most common aspect affected by urinary incontinence. Our sexual dysfunction incidence was higher than other studies and this fact could be explained by many surgeries having been done by residents.
\end{abstract}

\section{Keywords}

Prostate Cancer, Prostatectomy, Urinary Incontinence, Erectile Dysfunction, General Quality of

\footnotetext{
${ }^{*}$ Corresponding author.
}

How to cite this paper: Cornick, S.M., Corrêa, S.A.A., Girotti, M.E., Zambon, J.P., Alves, R.S. and de Almeida, F.G. (2015) Impact of Radical Prostatectomy on Urinary Incontinence, Erectile Dysfunction and General Quality of Life. Journal of Biosciences and Medicines, 3, 62-75. http://dx.doi.org/10.4236/jbm.2015.38007 


\section{Introduction}

Prostate cancer is the second most common type of tumor in Brazil and the sixth most common in the world. This disease accounts for about $10 \%$ of all cancers cases and its incidence rate is about six times higher in developed countries than in developing countries [1] [2]. The risk of prostate cancer is linked to aging, being directly proportional to the age of man [3]-[5]. The development of the prostate-specific antigen test (PSA) greatly contributed to earlier detections of prostate cancer cases. However, there is a dilemma in its use, as the test does not guarantee a reduction in mortality rates and the treatment may alter the quality of life of these patients [6][8]. Nowadays, patients diagnosed with localized prostate cancer have only the following treatment options: active surveillance, external beam radiotherapy, brachytherapy, and radical prostatectomy [9]. Radical prostatectomy is considered as a safe and effective treatment for localized prostate cancer [10]. The complications of radical prostatectomy are well established and it is estimated that post-prostatectomy urinary incontinence (PPUI) occurs with $5 \%$ to $25 \%$ of patients and erectile dysfunction (ED) with $16 \%$ to $86 \%$ of patients, even if techniques for nerve bundles preservation are adopted during the surgical procedure [11]-[13].

The PPUI has a strong negative impact on these patients' quality of life. It might be temporary, appearing in the first weeks immediately after the surgery and with progressive and spontaneous improvement after that. In case PPUI persists for longer than six months after surgery, the disease has a lower rate of spontaneous healing [14]. An ED caused by radical prostatectomy is related to injury of the neurovascular bundles of the corpora cavernosa. ED may also be temporary and it is estimated that the sexual function recovery period may last 18 months. Fortunately, patients under 65 years of age with no prior complaints of ED are better candidates to retain good erectile function, if submitted to surgical approaches with preservation of the neurovascular bundles [15]. Patients who underwent radical prostatectomy were evaluated by one-year post surgery and most of them stated to be satisfied with the results, despite the inherent morbidity of the surgery [16].

Quality of life was a vital concern for patients who underwent therapeutic intervention for prostate diseases [17]. The term quality of life needs the appreciation of broader parameters, rather than only post operatory symptoms, decrease in mortality and increase of life expectancy. Therefore, new approaches to assess the patients' perception of their illness and the needs and preferences for treatment, as well as the psychosocial aspect individually, beyond the traditional focus on the evolution of the disease, should be considered [18]-[20]. So far, Inoue et al. are the few authors who have studied the impact of radical prostatectomy in men (Japanese population) for a five-year period after the surgery. However, data from Japanese men can hardly be extrapolated to other populations, because, in agreement with O'Boyle, quality of life is highly influenced by culture [21]-[29]. On the other hand, Abouassaly et al. state quality of life changes after radical prostatectomy, due to complications of the treatment [30]-[33], although, up to now, there are few articles that assess the impact of radical prostatectomy on quality of life. This being the case, the impact of RRP on the overall quality of life and quality of life needs to be fully understood. The WHOQOL-Bref is the abbreviated version of the WHOQOL-100, detailed instrument, with 100 questions divided into six different topics, covering various questions related to quality of life. The WHOQOL-Bref is a reduced version of the WHOQOL-100, composed of four domains. All forms of the questionnaire are correlated, so the WHOQOL-Bref version can be converted to the original version of the questionnaire, the WHOQOL-100 [34]. The WHOQOL-Bref has been increasingly used to measure quality of life, but it has never been used to assess quality of life in patients who undergo radical prostatectomy. Among the main factors that lead to a poor quality of life in these patients, urinary incontinence and erectile dysfunction should be highlighted. Therefore, in this study, using the WHOQOL-Bref questionnaires, ICIQ-SF, OAB-q, IPSS and QS-M, we aim to evaluate the impact of voiding dysfunction and erectile dysfunction on the overall radical prostatectomy patients' quality of life for a six-month period after the surgical procedure.

\section{Patients and Methods}

\subsection{Patients}

Seventy-two patients with adenocarcinoma of the prostate who underwent radical retropubic prostatectomy between January 2008 and December 2009 were included and evaluated in this study using questionnaires in 
Urology, Escola Paulista de Medicina-UNIFESP Hospital.

Patients who were unable to complete the questionnaire due to cognitive impairments with inability to answer the questions asked, with cognitive, (psychiatric disease, senile dementia, Alzheimer's disease, etc.) and those who have failed to understand and clearly answer the questionnaires or were absent to the scheduled postoperatory returns at the outpatient unit at UNIFESP, where they were followed-up after surgery.

\subsection{Methods}

All patients were assessed by questionnaires. The questionnaires used were WHOQOL-Bref, ICIQ-SF, OAB-q, I-PSS, QS-M (attachments).

Patients were asked to complete the same questionnaire at four different points in time: preoperative, one, three and six months postoperatively. The QS-M was not applied in the first month after surgery, a period in which most of these patients have not regained sexual activity.

The first interview (preoperative) was conducted in the infirmary of the Discipline of Urology, Escola Paulista de Medicina/UNIFESP, located at Hospital São Paulo, upon admission to radical prostatectomy. The postoperatory interviews were conducted at the Voiding Dysfunction of the Discipline of Urology, Escola Paulista de Medicina/UNIFESP.

All the patients were interviewed by the same researcher during the data collection period.

The WHOQOL Bref consists of twenty six (26) questions. Two (02) of them assess general quality of life, and the other twenty-four (24) raise issues related to four domains: physical, psychological, social relationships and environment. These instruments have been translated to Brazilian Portuguese and validated to the Brazilian population by FLECK et al. 2000 [34].

The ICIQ-SF (International Consultation on Incontinence Questionnaire-Short Form) is a questionnaire that assesses the impact of urinary incontinence on the patients' quality of life and it also quantifies the magnitude of their urinary incontinence.

OAB-q (Overactive Bladder questionnaire): This questionnaire comprises eight questions that assess symptoms associated with overactive bladder.

I-PSS (International Prostatic Symptom Score): This questionnaire assesses symptoms of the lower urinary tract. Its last question is concerned to quality of life.

QS-M (Male Sexual Quotient): evaluate male sexual function in different ways, including sexual desire and interest, self-confidence, the quality of erection, ejaculation control, the ability to achieve orgasm and sexual satisfaction obtained by the man and given to his partner.

\subsection{Statistical Analysis}

Qualitative variables were summarized as absolute frequencies and percentages. Quantitative variables were described as means and standard deviations when normality assumption was considered appropriate or as median and interquartile range (IQR) otherwise. Changes related to urinary symptoms and loss of urine have been described by bar graphs over time. Scores obtained by the instruments OAB-q, ICIQ-SF, PSS-I, QS-M and WHOQOL-Bref were illustrated by graphs of the mean profiles obtained with $95 \%$ of confidence intervals. For comparisons between different groups and time-points, we used generalized linear models taking into account the dependence between measurements performed in the same patient.

Scores obtained by the OAB-q, ICIQ-SF, I-PSS, QS-M and WHOQOL-Bref testing were correlated using the Spearman correlation coefficients.

All analyses were performed with SPSS software (version 17.0), with a significance level of 5\%.

\section{Results}

Define abbreviations and acronyms the first time they are used in the text, even after they have been defined in the abstract. Abbreviations such as IEEE, SI, MKS, CGS, sc, dc, and rms do not have to be defined. Do not use abbreviations in the title or heads unless they are unavoidable.

\subsection{Patients' Characteristics}

We evaluated 72 patients with a mean age of 62 years of age $(\mathrm{SD}=7.7)$. The average PSA value was $7.4 \mathrm{ng} / \mathrm{ml}$ 
$(\mathrm{SD}=3.7)$. Patients' demographic characteristics and clinical background are shown in Table 1. Their pathological staging is described in Table 2. Next, we describe the scores obtained from the patients in different subsections. In the last one, we show the correlated data.

\subsection{Quality of Life versus Urinary Symptoms}

Using the I-PSS questionnaire, patients were asked how they would feel if kept their current urinary condition for the rest of their lifetime. In the preoperative period, $80.6 \%$ of patients rated their quality of life regarding urinary symptoms as "Good". This percentage dropped to $47.2 \%$ one month after the surgery. Perceptions of urinary symptoms scores improved three and six months after the surgery (Table 3 ).

Table 1. Demographic and background data.

\begin{tabular}{cl}
\hline Variables & n (\%) \\
Marital Status & \\
Married & $60(83.3 \%)$ \\
Single & $1.0(1.4 \%)$ \\
Divorced/separated & $4.0(5.6 \%)$ \\
Widower & $7.0(9.7 \%)$ \\
Education & \\
Iliterate & $7.0(9.7 \%)$ \\
Not Complete Elementary & $48(66.7 \%)$ \\
Not Complete Intermediate & $12(16.7 \%)$ \\
Not Complete Hight School & $1.0(1.4 \%)$ \\
College (not complete/complete) & $4.0(5.6 \%)$ \\
Alcoholism & $2.0(2.8 \%)$ \\
Smoking & $12(16.7 \%)$ \\
Smoking Time & $25(18 ; 35)$ \\
Systolic hipertension & $45(62.5 \%)$ \\
Others diseases & $12(16.7 \%)$ \\
Sexual Activity & $66(91.7 \%)$ \\
\hline
\end{tabular}

${ }^{* *}$ Medium (standard deviation); ${ }^{\S}$ Median (IIQ).

Table 2. Distribution of patients according to pathological staging.

\begin{tabular}{cc}
\hline Staging & $\mathbf{n}(\%)$ \\
\hline pt1a & $1.0(1.4 \%)$ \\
pt2a & $6.0(8.6 \%)$ \\
pt2b & $4.0(5.7 \%)$ \\
pt2c & $1.0(1.4 \%)$ \\
pt2c & $52(74.3 \%)$ \\
pt3a & $8(11.1)$ \\
Total & $72(100.0 \%)$ \\
\hline
\end{tabular}


Table 3. Quality of life due to urinary symptoms.

\begin{tabular}{ccccc}
\hline Characteristics & \multicolumn{3}{c}{ Time evaluation } \\
\hline Pre & $\mathbf{1}$ month & $\mathbf{3}$ months & $\mathbf{6}$ months \\
\hline Pood (happy, well, overall good and regular) & $58(80.6 \%)$ & $34(47.2 \%)$ & $45(62.5 \%)$ & $55(76.4 \%)$ \\
Total & $14(19.4 \%)$ & $38(52.8 \%)$ & $27(37.5 \%)$ & $17(23.6 \%)$ \\
Comparations & $72(100.0 \%)$ & $72(100.0 \%)$ & $72(100.0 \%)$ & $72(100.0 \%)$ \\
1 month $\times$ pré & $\mathrm{P}$ & & & \\
3 months $\times$ pré & $<0.001^{*}$ & & & \\
6 meses $\times$ pré & $0.016^{*}$ & & & \\
3 months $\times 1$ month & 0.525 & & \\
6 months $\times 1$ month & 0.065 & & \\
6 months $\times 3$ months & $<0.001^{*}$ & & \\
\hline
\end{tabular}

*Significant difference. P-value obtained from the chi-square test.

\subsection{Urinary Incontinence Assessed by the ICIQ-SF Instrument}

The answers to the question "When was the last time you lost urine without meaning it" are represented in Table 4. It is noteworthy that, in the pre-surgery questionnaire, $75.0 \%$ of the patients stated that had never lost urine. One month after surgery, only $11.1 \%$ of patients remained stating that had never lost urine, while $69.4 \%$ of patients reported "I lose when I cough or sneeze". At the first post-surgical time point, three months, the most frequently answer was "I miss when I'm doing physical activities", mentioned by $65.3 \%$ of patients. This condition was also reported at the six-month time-point by $53.7 \%$ of patients.

\subsection{Behavior Assessment Scores}

Behavior scores were obtained with the instruments OAB-q, ICIQ-SF, PSS-I, QS-M and WHOQOL and are represented in the graphs of average profiles 1-11. Comparisons between scores obtained over time-points are shown in Table 5.

On average, the OAB-q score (Figure 1(a)) shows a significant increase in the first month after surgery, followed by a decrease in the following months. Noteworthy to mention that the score values are very similar at time-points preoperative compared to six-month postoperative and quite distinct at time-points preoperative compared to one-month postoperative.

Regarding the ICIQ-SF score (Figure 1(b)), there is a significant increase in the first month and a gradual reduction throughout the postoperative period. Nevertheless, this reduction is not enough to regain the medium values observed in the preoperative period. As for the OAB score, score values variability was high among different patients.

In the I-PSS scores (Figure 1(c)), highest averages were observed one month after surgery, followed by a significant decrease at the postoperative time-points (one, three and six months). Curiously, at the six-month time-point scores obtained were lower than those obtained for the preoperative baseline.

In the QS-M score (Figure 1(d)), we observed a significant decrease in the scores only at the three-month time-point, decrease also observed after 6 months of the surgery. All postoperatively score values were significantly lower than the preoperative ones.

When considering the physical domain of the WHOQOL (Figure 2(a)), there is a significant decrease between the preoperative period and the first month measures. Between the first and third month there is a significant increase in these values, followed by stabilization of the values, so that the values obtained at 6 months were similar to those obtained before surgery.

Regarding the psychological domain (Figure 2(b)), we find a significant decrease in the values in one month after surgery, followed by an increase between one and six months evaluations. 


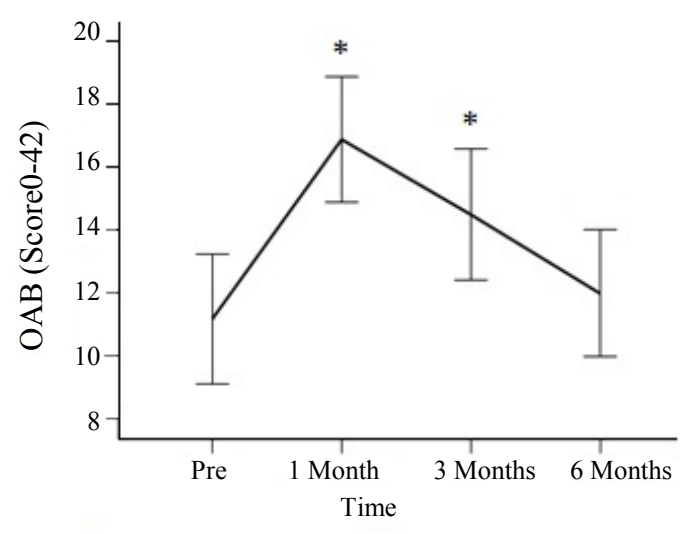

(a)

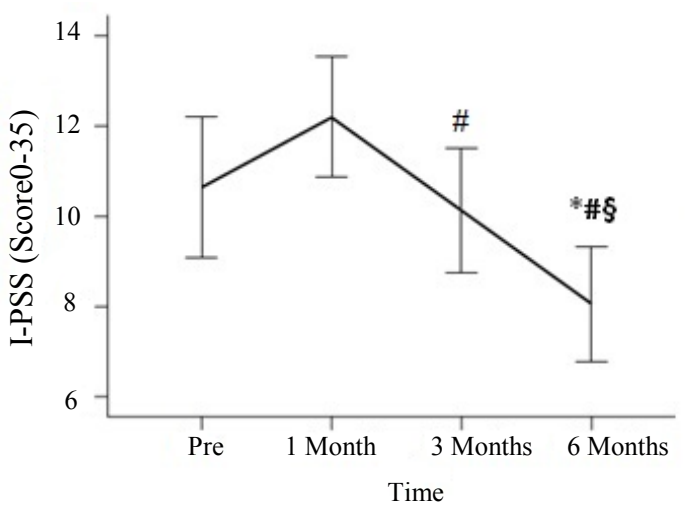

(c)

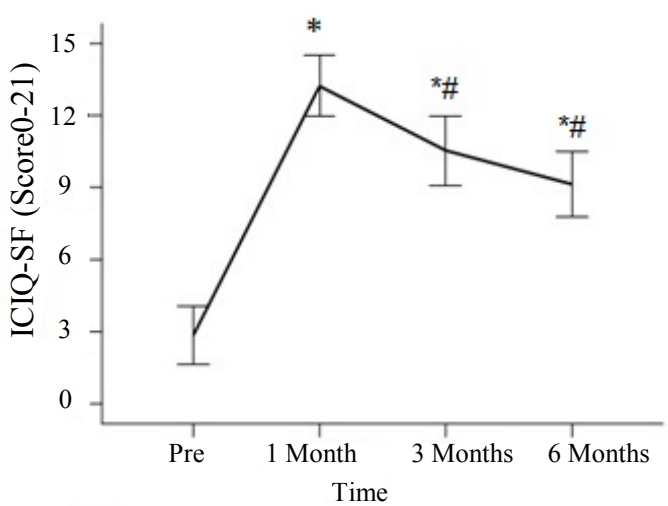

(b)

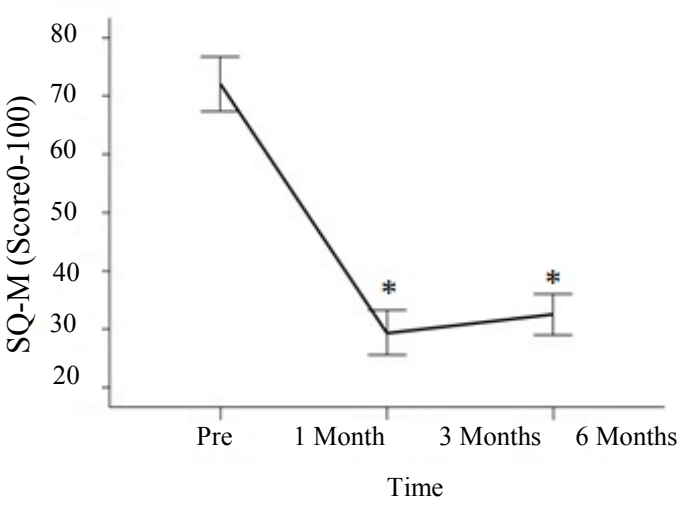

(d)

Figure 1. Average profile and $95 \%$ of confidence intervals for OAB scores (a); ICIQ-SF (b); I-PSS (C); QS-M (d); ${ }^{*}$ P-value < 0.05 when compared with the pre moment. ${ }^{\#} \mathrm{P}$-value $<0.05$ when compared to one $(01)$ month. ${ }^{\S} \mathrm{P}$-value $<0.05$ when compared to three (03) months. OAB, overactive bladder; ICIQ-SF, international consultation on incontinence questionnaire; SQ-M, sexual quocient-male.

\section{Table 4. Responses to the question: When you lose urine?}

\begin{tabular}{ccccc}
\hline Characteristics & \multicolumn{4}{c}{ Time Avaliation } \\
\cline { 2 - 5 } Never & Pre & $\mathbf{1}$ month & $\mathbf{3}$ months & $\mathbf{6}$ months \\
\cline { 2 - 5 } Lost before reaching the bathroom & $54(75.0 \%)$ & $8.0(11.1 \%)$ & $11(15.3 \%)$ & $13(19.4 \%)$ \\
I lose when I cough or sneeze & $15(20.8 \%)$ & $28(38.9 \%)$ & $18(25.4 \%)$ & $12(17.9 \%)$ \\
I lose when I'm sleeping & $1.0(1,4 \%)$ & $50(69.4 \%)$ & $43(59.7 \%)$ & $34(50.7 \%)$ \\
I lose when I'm doing physical activities & $2.0(2.8 \%)$ & $31(43.1 \%)$ & $14(19.4 \%)$ & $10(14.9 \%)$ \\
Lose when finished urinating and I'm wearing & $2.0(2.8 \%)$ & $47(65.3 \%)$ & $47(65.3 \%)$ & $36(53.7 \%)$ \\
Lost without obvious reason & $6.0(8.3 \%)$ & $26(36.1 \%)$ & $21(29.2 \%)$ & $10(14.9 \%)$ \\
I lose all the time & $3.0(4.2 \%)$ & $29(40.3 \%)$ & $18(25.0 \%)$ & $22(32.8 \%)$ \\
\hline
\end{tabular}

Described percentages of total responses to each statement in each instant of time.

When the social field is considered (Figure 2(c)), there is a significant decrease in the mean values after the first month, with no significant changes in the following evaluations. After 6 months, the WHOQOL social domain score is significantly lower than that observed before surgery.

In the environment domain (Figure 2(d)), there is a decrease in values obtained in the postoperative time- 


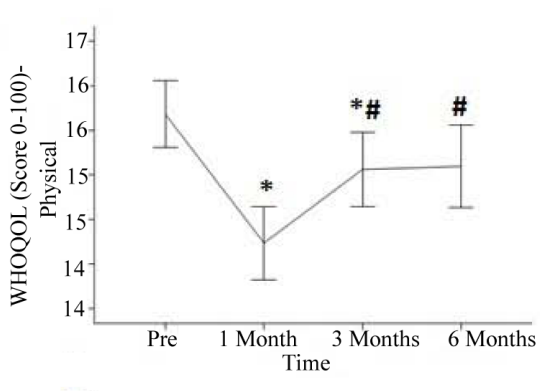

(a)

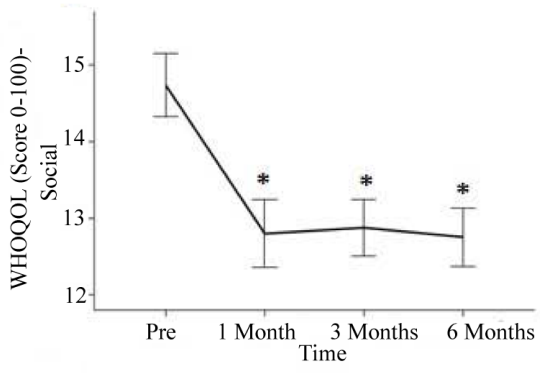

(c)

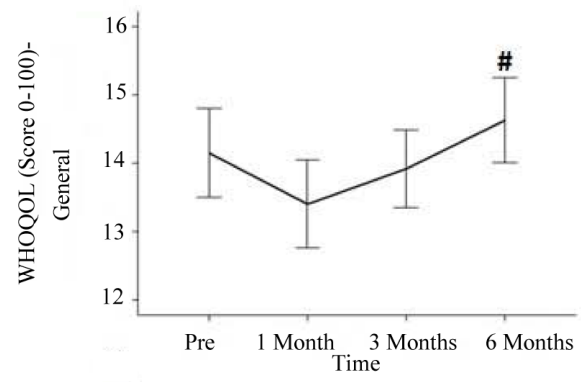

(e)

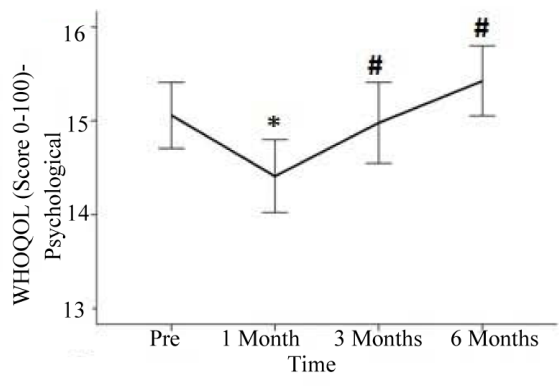

(b)

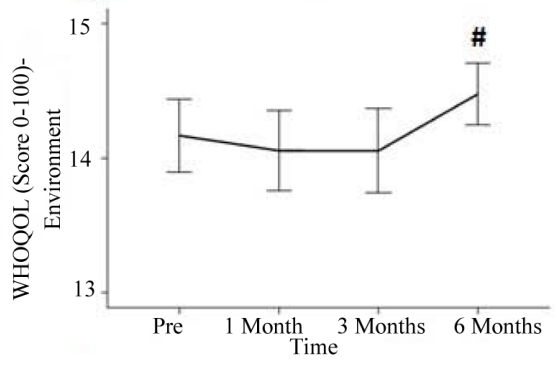

(d)

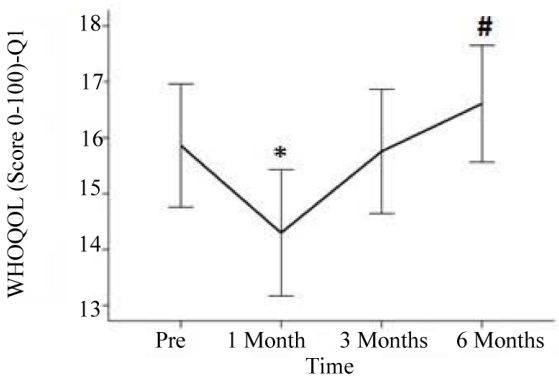

(f)

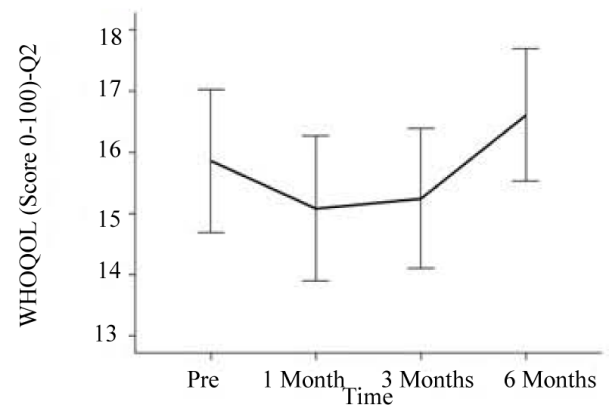

(g)

Figure 2. Average profile and 95\% of confidence intervals for the WHOQOL score-physical domains (a); Psychology (b); social (c); environment (d); general (e); WHOQOL-Q1 (f); WHOQOL-Q2 (g). " P-value < 0.05 when compared with the pre. "P-value $<0.05$ when compared to one (01) month. ${ }^{\S} \mathrm{P}$-value $<0.05$ when compared to three $(03)$ months. WHOQOL, World Health Organization for Quality of Life. Q1, Question 1; Q2, Question 2.

point, followed by significant increases between the three and sixth months. Last collected values are similar to those obtained before surgery.

As to the overall score WHOQOL (Figure 2(d)), there is no significant decrease in the average value during the first month after surgery, and a significant increase at the six-month time-point, so that the score values obtained at the last collection were significantly higher than those observed in the first month of monitoring. 
Table 5. Comparison of scores over time.

\begin{tabular}{|c|c|c|c|c|c|}
\hline \multirow{3}{*}{$\begin{array}{c}\text { Score } \\
\text { OAB-q }\end{array}$} & \multicolumn{5}{|c|}{ Time instant } \\
\hline & Pre & \multicolumn{2}{|c|}{1 month } & \multirow{2}{*}{$\begin{array}{c}3 \text { months } \\
14.49(1.04)^{*}\end{array}$} & \multirow{2}{*}{$\begin{array}{c}6 \text { months } \\
11.97(1.01)^{\#}\end{array}$} \\
\hline & $11.46(1.09)$ & 17.31 & $(1.06)^{*}$ & & \\
\hline ICIQ SF & $3.03(0,65)$ & \multicolumn{2}{|c|}{$13.24(0.66)^{*}$} & $10.54(0.73)^{* \#}$ & $9.13(0.69)^{* \#}$ \\
\hline I-PSS & $10.67(0.85)$ & \multicolumn{2}{|c|}{$12.64(0.71)$} & $10.13(0.69)^{\#}$ & $8.06(0.64)^{* \# \AA}$ \\
\hline QS-M & $72.42(2.47)$ & & - & $29.31(1.93)^{*}$ & $32.54(1.78)^{*}$ \\
\hline Physical-WHOQOL & $15.71(0.20)$ & 14.31 & $(0.22)$ & $15.10(0.21)^{* \#}$ & $15.10(0.23)^{\#}$ \\
\hline Psychological-WHOQOL & $15.01(0.18)$ & 14.44 & $(0.20)^{*}$ & $15.01(0.22)^{\#}$ & $15.42(0.19)^{\#}$ \\
\hline Social-WHOQOL & $14.63(0.22)$ & 12.65 & $(0.24)^{*}$ & $12.85(0.19)$ & $12.76(0.19)^{*}$ \\
\hline Environment-WHOQOL & $14.13(0.15)$ & \multicolumn{2}{|c|}{$14.06(0.16)$} & $14.07(0.16)$ & $14.48(0.12)^{\#}$ \\
\hline General-WHOQOL & $14.36(0.32)$ & \multicolumn{2}{|c|}{$13.50(0.34)$} & $14.00(0.28)$ & $14.63(0.31)^{\#}$ \\
\hline Q1-WHOQOL & $16.23(0.55)$ & 14.58 & $(0.59)^{*}$ & $15.89(0.55)$ & $16.60(0.52)^{\#}$ \\
\hline Q2-WHOQOL & $16.15(0.59)$ & \multicolumn{2}{|c|}{$15.10(0.64)$} & $15.36(0.57)$ & $16.60(0.54)$ \\
\hline
\end{tabular}

Data were presented as mean (standard error). ${ }^{*} \mathrm{P}$-value $<0.05$ when compared to the pre (significant effect of time); ${ }^{\# P} \mathrm{P}$-value $<0.05$ when compared 1 month ago (significant effect of time); ${ }^{\S}$ P-value $<0.05$ when compared to 3 months (mean time effect).

Considering the WHOQOL score-Question 1 (How would you evaluate your quality of life?-Figure 2(f)), it is noticed that the values observed in the first month are statistically lower than those observed before surgery. Values increase at the three and six-month time-points, being the last collected values similar to those obtained in the preoperative period.

Regarding the WHOQOL score-Question 2 (How satisfied are you with your health?—Figure 2(g)), no significant changes of the average values were observed over the six-month follow-up.

\subsection{Behavior Assessment Scores Associated with Continence and Sexual Function}

Patients were considered continents, if making use of up to one absorbent within a 24-hour period and potent, if able to maintain erection for satisfactory sexual intercourse. All patients were considered continent preoperatively and after the six-month follow-up period, $76.4 \%$ of these patients remained continent. Although $25 \%$ of patients reported some degree of urinary incontinence preoperatively, none of them reported wearing absorbent.

In Table 6, we can observe the scores obtained for continent and for incontinent patients. Moreover, we could also observe that patients with incontinence obtained, on average, worse scores than those obtained by continents patients in the OAB-q, ICIQ-SF and I-PSS, tests, but there was no statistically significant difference in the erectile dysfunction scores between continent and incontinent patients obtained by the WHOQOL (Table 6).

No statistically significant differences were observed between patients with and without erectile dysfunction. Among the seventy-two patients included in this study, sixty-six of them reported to have sexual activity before the surgery and only six of them reported no sexual activity at all (Table 7).

Among these sixty-six patients who used to have sexual intercourse before surgery, Erectile function was conserved (QS-M Question-6: After the sexual arousal his erection sufficiently rigid to ensure a satisfactory sexual intercourse?) in fifty-eight of them. The other eight patients did not clearly answer this question. Among these fifty-eight patients, $48(83 \%)$ had erectile dysfunction at the six-month time-point and only ten patients $(17.0 \%)$ reported not having experienced erectile dysfunction. The six patients who had no sexual activity before surgery maintained erectile dysfunction at six months.

\subsection{Correlations between the Assessment Scores}

Quality of life according to urinary symptoms questionnaire item I-PSS with the WHOQOL social OAB-q, ICIQ-SF and QS-M values obtained at different time-points were compared using the Spearman correlation 
Table 6. Comparisons between continent and incontinent compared to scores.

\begin{tabular}{cccc}
\hline Score & Continents & Incontinent & P-value \\
\hline General-WHOQOL & $\mathbf{( n = 5 5 )}$ & $\mathbf{( n = 1 7 )}$ & 0.522 \\
Physics-WHOQOL & $14.7(2.7)$ & $14.2(2.2)$ & 0.208 \\
Psychological-WHOQOL & $15.4(1.9)$ & $14.8(1.6)$ & 0.102 \\
Social-WHOQOL & $15.4(1.5)$ & $14.7(1.4)$ & 0.343 \\
Environmental-WHOQOL & $12.8(1.7)$ & $12.4(1.3)$ & 0.206 \\
ICIQ-SF & $14.5(1.0)$ & $14.1(1.2)$ & $<0.001$ \\
OAB-q & $7.3(5.4)$ & $13.5(3.8)$ & $<0.001$ \\
I-PSS & $8.4(6.2)$ & $16.8(7.0)$ & $10.8(4.7)$ \\
\hline
\end{tabular}

Table 7. Erectile situation at the end of follow-up according to sexual activity observed before surgery.

\begin{tabular}{cccc}
\hline Sexual activity before & & Erectile situation at 6 months & \\
\hline Surgery & Without erectile & With erectile & Total \\
& Dysfunction & Dysfunction & $58(100.0 \%)$ \\
Yes & $10.0(17.0 \%)$ & $48.0(83.0 \%)$ & $6.00(100.0 \%)$ \\
No & 0.00 & $6.00(100.0 \%)$ & \\
\hline
\end{tabular}

coefficients (Table 8).

At all time-points, positive correlations were observed between quality of life scores and I-PSS scores related to urinary symptoms (ICIQ-SF and OAB-q). The correlations of the I-PSS score with the quality of life measured by WHOQOL and the QS-M were of low intensity.

\section{Discussion}

In the present study we evaluated 72 patients who underwent radical prostatectomy to determine the impact ofsurgery on the overall quality of life and on urinary incontinence and erectile function, before surgery and at three different time-points of the postoperative period (six months). In general, the overall quality of life evaluation assessed by the WHOQOL, we observed no difference in the total score of the questionnaire. Similarly, Perez et al. (1995) noted that although patients they reported erectile dysfunction and some degree of urinary incontinence, quality of life was not affected after radical prostatectomy [35]. When we analyze the domains of WHOQOL alone, we observe, however, that radical prostatectomy had a significant impact on the social domain, clearly associating erectile dysfunction with interpersonal relationship. Our evaluation, restricted by the sixth month postoperatively, demonstrates that radical prostatectomy adversely affects sexual function, in agreement with Namiki et al. (2008), who did not observe improvement in sexual dysfunction after a year of surgery. Other studies, with longer follow-ups, reported gradual improvement of erectile dysfunction up to eighteen months after prostatectomy [36].

In the QS-M questionnaire, specific to sexual evaluation, there is a significant decrease in the score values obtained at the last evaluation sessions (six months) of our study. This finding is consistent with Fowler et al., YEAR's observations of the negative effects on quality of life caused by loss or impairment of sexual and urinary functions, but points out that the gradual adaptation process that aims to eliminate the adverse effects caused by radical prostatectomy [37].

Patient's perception of lower urinary tract symptoms shows that worsening of symptoms in one month after surgery, followed by gradual recovery. At the six-month time-point, the urinary questionnaires OAB-q, I-PSS and the physical, environmental, Q1 (How would you rate your quality of life?) And Q2 (How satisfied are you with your health?) WHOQOL revealed us scores values similar to the ones obtained in the preoperative period. 
Table 8. Correlations between quality of life according to urinary symptoms and other scores.

\begin{tabular}{|c|c|c|c|c|}
\hline \multirow{3}{*}{ Score } & \multicolumn{4}{|c|}{ Correlation with quality of life according urinary symptoms } \\
\hline & & & At time & \\
\hline & Pre & 1 month & 3 months & 6 months \\
\hline \multirow{2}{*}{ Social-WHOQOL } & -0.229 & -0.429 & -0.047 & -0.237 \\
\hline & $(0.041)^{\S}$ & $(<0.001)^{\S}$ & (0.693) & $(0.053)$ \\
\hline \multirow{2}{*}{ Q-OAB-q } & 0.555 & 0.441 & 0.507 & 0.681 \\
\hline & $(<0.001)^{\S}$ & $(<0.001)^{\S}$ & $(<0.001)^{\S}$ & $(<0.001)^{\S}$ \\
\hline \multirow{2}{*}{ ICIQ SF } & 0.587 & 0.531 & 0,743 & 0.799 \\
\hline & $(<0.001)^{\S}$ & $(<0.001)^{\S}$ & $(<0.001)^{\S}$ & $(<0.001)^{\S}$ \\
\hline \multirow{2}{*}{ QS-M } & -0.258 & & -0.207 & 0.001 \\
\hline & $(0.021)^{\S}$ & & $(0.081)$ & $(0.991)$ \\
\hline
\end{tabular}

${ }^{\S}$ Statistically significant correlation with $\mathrm{P}<0.05$; Data described in the Spearman correlation coefficient (P-value).

It also demonstrated an increase in the psychological domain of WHOQOL score, showing an improvement of the patient's emotional state, as observed in other studies [35]-[38].

Emotional state improvements might reflect the gradual and partial recovery of urinary problems, and eventually getting adapted to these problems or simply by modifying his concept of quality of life over time.

In the present study the ICIQ-SF questionnaire assessing urinary incontinence had an increase in the value of the score, demonstrating that urinary continence was not fully recovered at six-month postoperatively time-point. Pre-operative questionnaires demonstrated that $25 \%$ of patients had some degree of incontinence, a finding similar to that found by Korfage in 2005, where $12 \%$ of patients had incontinence before surgery for prostate cancer [39].

Urinary incontinence in elderly patients may be multifactorial. Neurological disorders, cognitive impairment and medications are some of the factors involved. Radical prostatectomy seems to be an aggravating factor in a situation in which urinary incontinence is likely to be already established.

The I-PSS questionnaire demonstrated an improvement of the urinary tract symptoms after radical prostatectomy. This improvement might be due to some of these patients having symptoms of storage and emptying of the lower urinary tract related to increased prostatic hyperplasia. Therefore surgical removal of the gland relieves urinary obstruction. In agreement with our study, Slova Lapor in 2007 observed the same results. Men with lower urinary tract moderate or severe symptoms show gradual improvement after radical prostatectomy [40].

To assess how urinary incontinence affects quality of life measured by WHOQOL general, patients were divided into two groups: continents (up to one absorbent within a $24 \mathrm{~h}$ period) and incontinent. The comparison between these groups showed no difference in the quality of life measured with WHOQOL general. This finding may be explained by the patient's adaptation to the adverse effects of radical prostatectomy, as noted by Arai et al., for whom patients are willing to accept some comorbidities for the benefit of survival after prostate cancer [41]. In addition to that, Martin et al., 2011 concluded that urinary incontinence has low impact on quality of life, although $31 \%$ of patients have some level of anxiety due to urinary symptoms [42]. Hoffman et al. in 2003 found that among those who developed post-prostatectomy urinary incontinence, $75 \%$ reported that the inconvenience was small [43].

According to the WHOQOL (World Healh Organization for Quality of Life), the concept of quality of life is individual. The idea of health status, consisting of physical, functional, psychological and social interaction differs between individuals, and is directly related to the socio-cultural context in which the individual is inserted, making of it not a unique concept, accepted as synonymous with quality of life [34] [44].

Quality of life evaluations of the I-PSS questionnaire with WHOQOL social domain, OAB-q, ICIQ-SF and QS-M obtained at all different time-points, provided positive correlations between quality of life score and the I-PSS scores related to urinary symptoms (ICIQ-SF and OAB-q). Correlations of the I-PSS score with quality of 
life measured by the WHOQOL and the QS-M were of low intensity. Similar findings were obtained by, although the study involved patients with benign prostatic hyperplasia. Moreover, Haltbakk et al. in 2011 concluded that the WHOQOL instrument may be very comprehensive and unable to detect the influence of specific symptoms on quality of life. Despite the WHOQOL is an instrument accepted by the World Health Organization, it might not have been properly adapted to detect quality of life changes in certain group of patients [45]. Historically, the SF-36 (Short Form Health Survey) is the most frequently used questionnaire to assess quality of life of patients who underwent radical prostatectomy or other forms of treatment. Worthy to mention the studies conducted by Jim et al., who used the SF-36 associated with the UCLA Prostate Cancer Index to evaluate the characteristics of the patient and of the tumor to predict continence, sexual function and quality of life for up to one year after the surgery and concluded that patients aging less than 65 years are more likely to return to continence base, sexual function and quality of life [46].

In our group of patients, we could observe a state of resignation concerning to urinary symptoms and to erectile dysfunction, while maintaining the expectation of symptom improvement over time. In this short follow-up, it is likely that the main concern of patients remained targeted at the malignant disease, since quality of life is the perception that the patient has of himself, a perception that can change along the postoperative period.

The rehabilitation of these patients should not only target the physical aspect, but also psychological and social aspects that directly affect their quality of life. Aaronson (1990) and Buron et al. (2007) stated that studies on quality of life in oncology should consider the various needs and perception of each individual, in order to assess the subjective aspects and consider personal aspects associated with social and cultural classes [47] [48].

Some authors believe that quality of life is directly linked to better survival rates and consider the necessity to build more consistent methods to assess cancer patients' quality of life, reflecting the evolutionary changes of the disease. The same patient can adjust his quality of life perception within time, therefore change in the same questionnaire should be reapplied at different times postoperatively [49]-[52].

For some researchers, measuring the perceived quality of life enriches clinical research and therefore the questionnaires to assess patients' perceptions are of utmost importance [53].

Our study contributes to the evaluation of patients of the public health service with their own socioeconomic and cultural characteristics and quality of life perceptions. The ideal questionnaire for this group of patients has yet to be developed and we hope that this study can be an useful tool in the assembly of this clinical research instrument.

\section{Conclusions}

Radical prostatectomy adversely affects quality of life, but the effects are temporary, with return to the preoperative levels after six months, except for the social domain of the WHOQOL.

The lower urinary tract symptoms assessed by the I-PSS improved after radical prostatectomy. Urinary continence measured by the ICIQ-SF worsened after radical prostatectomy in all periods. Erectile dysfunction worsened after radical prostatectomy at all checked time-points.

There is no difference in the quality of life assessment of WHOQOL between continent and incontinent patients. The lower urinary tract symptoms as measured by the OAB-q worsened temporarily, but returned to the preoperative levels six months after the surgery.

Quality of life scores, as measured by the I-PSS, correlates with the OAB-q and ICIQ-SF scores, but not with the ones obtained by the WHOQOL and QS-M.

\section{References}

[1] Instituto Instituto Nacional do Câncer (2012) Estimativas 2014 http://www.inca.gov.br/estimativa/2014/

[2] Parkin, D.M., Bray, F.I. and Devesa, S.S. (2001) Cancer Burden in the Year 2000: The Global Picture. European Journal of Cancer, 37, 4-66. http://dx.doi.org/10.1016/S0959-8049(01)00267-2

[3] Sakr, W.A., Grignon, D.J., Haas, G.P., Heilbrun, L.K., Pontes, J. and Crissman, J.D. (1996) Age and Racial Distribution of Prostatic Intraepithelial Neoplasia. European Urology, 30, 138-144.

[4] Crawford, E.D. (2003) Epidemiologia do câncer de próstata. Urologia, 62, 3-12. http://dx.doi.org/10.1016/j.urology.2003.10.013

[5] Bubendorf, L., Schopfer, A., Wagner, U., Sauter, G., Moch, H., Willi, N., Gasser, T.C. and Mihatsch, M.J. (2000) Metastatic Patterns of Prostate Cancer: An Autopsy Study of 1589 Patients. Human Pathology, 31, 578-583. 
http://dx.doi.org/10.1053/hp.2000.6698

[6] Stenman, U.H., Abrahamsson, P.A., Aus, G., Lilja, H., Bangma, C., Hamdy, F.C., Boccon-Gibod, L. and Ekman, P. (2005) Prognostic Value of Serum Markers for Prostate Câncer. Scandinavian Journal of Urology and Nephrology, 39, 64-81. http://dx.doi.org/10.1080/03008880510030941

[7] Gomella, L.G., Liu, X.S., Trabulsi, E.J., Kelly, W.K., Myers, R., Showalter, T., Dicker, A. and Wender, R. (2011) Screening for Prostate Cancer: The Current Evidence and Guidelines Controversy. The Canadian Journal of Urology, 18, 5875-5883.

[8] Yossepowitch, O. (2007) Prostate Câncer in Men with Serum PSA of $<4$ ng/ml: Under-Diagnosed or Over-Treated? European Urology, 53, 686-688. http://dx.doi.org/10.1016/j.eururo.2007.10.067

[9] Zerbib, M., Zelefsky, M.J., Higano, C.S. and Carroll, P.R. (2008) Conventional Treatments of Localized Prostate Cancer. Urology, 72, S25-S35.

[10] Arai, Y., Okada, T., Egawa, S., Matsumoto, K., Tobisu, K., Sagiyama, K., Sumiyoshi, Y., Hashine, K., Kawakita, M., Matsuda, T., Kakehi, Y., Terachi, T. and Ogawa, O. (2000) Radical Retropubic Prostatectomy: Time Trends, Morbidity and Mortality in Japan. BJU International, 85, 287-294. http://dx.doi.org/10.1046/j.1464-410x.2000.00468.x

[11] Escobar, F.R. and Bertrán, P.A. (2009) Incontinencia urinaria post-prostatectomía. El esfinter artificial. Archivos Españoles de Urología, 62, 838-844.

[12] Nandipati, K.C., Raina, R., Agarwal, A. and Zippe, C.D. (2006) Erectile Dysfunction Following Radical Retropubic Prostatectomy: Epidemiology, Pathophysiology and Pharmacological Management. Drugs \& Aging, 23, 101-117. http://dx.doi.org/10.2165/00002512-200623020-00002

[13] Ayyathurai, R., Manoharan, M., Nieder, A.M., Kava, B. and Soloway, M.S. (2008) Factors Affecting Erectile Function after Radical Retropubic Prostatectomy: Results from 1620 Consecutive Patients. BJU International, 101, 833-836. http://dx.doi.org/10.1111/j.1464-410X.2007.07409.x

[14] Moore, K.N., Truong, V., Estey, E. and Voaklander, D.C. (2007) Urinary Incontinence after Radical Prostatectomy: Can Men at Risk Be Identified Preoperatively? Journal of Wound Ostomy \& Continence Nursing, 34, 270-279. http://dx.doi.org/10.1097/01.won.0000270821.91694.56

[15] Raina, R., Lakin, M.M., Agarwal, A., Mascha, E., Montague, D.K., Klein, E. and Zippe, C.D. (2004) Efficacy and Factors Associated with Successful Outcome of Sildenafil Citrate Use for Erectile Dysfunction after Radical Prostatectomy. Urology, 63, 960-966. http://dx.doi.org/10.1016/j.urology.2003.12.012

[16] Arai, Y., Okubo, K., Aoki, Y., Maekawa, S., Okada, T., Maeda, H., Ogawa, O. and Kato, T (1999) Patient-Reported Quality of Life after Radical Prostatectomy for Prostate Cancer. International Journal of Urology, 6, 78-86. http://dx.doi.org/10.1046/j.1442-2042.1999.00629.x

[17] Bola, A.J., Gambill, B., Fabrizio, M.D., Davis, J.W., Dado, R.W., Lynch, D.F., Shaves, M. and Schellhammer, P.F. (2006) Prospective Longitudinal Comparative Study of Early Health-Related Quality-of-Life Outcomes in Patients Undergoing Surgical Treatment for Localized Prostate Cancer: A Short-Term Evaluation of Five Approaches from a Single Institution. Journal of Endourology, 20, 723-731. http://dx.doi.org/10.1089/end.2006.20.723

[18] Brawer, M.K., Chetner, M.P., Beatie, J., Buchner, D.M., Vessella, R.L. and Lange, P.H. (1992) Screening for Prostatic Carcinoma with Prostate Specific Antigen. Journal of Urology, 147, 841-845.

[19] Fleck, M.P., Leal, O.F., Louzada, S., Xavier, M., Chachamovich, E., Vieira, G., Santos, L. and Pinzon, V. (1999) Desenvolvimento da versão em português do instrumento de avaliação de qualidade de vida da OMS (WHOQOL-100). The Revista Brasileira de Psiquiatria, 21, 19-28. http://dx.doi.org/10.1590/S1516-44461999000100006

[20] Higginson, I.J. and Carr, A.J. (2001) Measuring Quality of Life: Using Quality of Life Measures in the Clinical Setting. British Medical Journal, 322, 1297-300. http://dx.doi.org/10.1136/bmj.322.7297.1297

[21] O’Boyle, C.A., McGee, H., Hickey, A., O’Malley, K. and Joyce, C.R.B. (1992) Individual Quality of Life in Patients Undergoing Hip Replacement. The Lancet, 339, 1088-1091. http://dx.doi.org/10.1016/0140-6736(92)90673-Q

[22] Hampson, L.A., Cowan, J.E., Zhao, S., Carroll, P.R. and Cooperberg, M.R. (2015) Impact of Age on Quality-of-Life Outcomes after Treatment for Localized Prostate Cancer. European Urology, 68, 180-486. http://dx.doi.org/10.1016/j.eururo.2015.01.008

[23] Orley, J., Saxena, S. and Herrman, H. (1998) Quality of Life and Mental Illness: Reflections from the Perspective of the WHOQOL. The British Journal of Psychiatry, 172, 291-293. http://dx.doi.org/10.1192/bjp.172.4.291

[24] The WHOQOL Group (1997) World Health Organization, WHOQOL: Measuring Quality of Life. WHO, Geneva.

[25] Fleck, M.P., Louzada, S., Xavier, M., Chachamovich, E., Vieira, G., Santos, L. and Pinzon, V. (1999) Aplicação da versão em português do instrumento de avaliação de qualidade de vida da Organização Mundial da Saúde (WHOQOL100). Revista de Saúde Pública, 33, 198-205. http://dx.doi.org/10.1590/S0034-89101999000200012

[26] The WHOQOL Group (1995) World Health Organization Quality of Life Assessment (WHOQOL): Position Paper 
from World Health Organization. Social Science \& Medicine, 41, 1403-1409.

http://dx.doi.org/10.1016/0277-9536(95)00112-K

[27] Fleck, M.P. (2000) O instrumento de avaliação de qualidade de vida da Organização Mundial da Saúde (WHOQOL100): Características e perspectivas. Ciência \& Saúde Coletiva, 5, 33-38. http://dx.doi.org/10.1590/S1413-81232000000100004

[28] McHorney, C.A., Ware Jr., J.E. and Raczek, A.E. (1993) The MOS 36-Item Short-Form Health Survey (SF-36): II. Psychometric and Clinical Tests of Validity in Measuring Physical and Mental Health Constructs. Medical Care, 31, 247-263. http://dx.doi.org/10.1097/00005650-199303000-00006

[29] Litwin, M.S., Hays, R.D., Fink, A., Ganz, P.A., Leake, B. and Brook, R.H. (1998) The UCLA Prostate Cancer Index: Development, Reliability, and Validity of A health-Related Quality of Life Measure. Medical Care, 36, 1002-1012. http://dx.doi.org/10.1097/00005650-199807000-00007

[30] Abouassaly, R., Lane, B.R., Lakin, M.M., Klein, E.A. and Gill, I.S. (2006) Ejaculatory Urine Incontinence after Radical Prostatectomy. Urology, 68, 1248-1252. http://dx.doi.org/10.1016/j.urology.2006.08.1097

[31] Iyigun, E., Ayhan, H. and Tastan, S. (2011) Perceptions and Experiences after Radical Prostatectomy in Turkish Men: A Descriptive Qualitative Study. Applied Nursing Research, 24, 101-109. http://dx.doi.org/10.1016/j.apnr.2009.04.002

[32] O’Boyle, C.A., McGee, H., Hickey, A., O’Malley, K. and Joyce, C.R.B. (1992) Individual Quality of Life in Patients Undergoing Hip Replacement. The Lancet, 339, 1088-1091. http://dx.doi.org/10.1016/0140-6736(92)90673-Q

[33] Inoue, S., Shiina, H., Hiraoka, T., Wake, K., Sumura, M., Honda, S., Urakami, S., Igawa, M. and Usui, T. (2009) Five Year Longitudinal Effect of Radical Perineal Prostatectomy on Health-Related Quality of Life in Japanese Men, Using General and Disease Specific Measures. BJU International, 104, 1077-1084. http://dx.doi.org/10.1111/j.1464-410X.2009.08491.x

[34] Fleck, M.P.A., Louzada, S., Xavier, M., Chanchamovich, E., Vieira, G., Santos, L. and Pinzon, V. (2006) Aplicação da versão em português do instrumento abreviado de avaliação de qualidade de vida WHOQOL-BREF. Revista de Saúde Pública, 40, 785-791. http://dx.doi.org/10.1590/S0034-89102006000600007

[35] Perez, M.A., Meyerowitz, B.E., Lieskovsky, G., Skinner, D.G., Reynolds, B. and Skinner, E.C. (1997) Quality of Life and Sexuality Following Radical Prostatectomy in Patients with Prostate Cancer Who Use or Do Not Use Erectile Aids. Urology, 50, 740-746. http://dx.doi.org/10.1016/S0090-4295(97)00327-0

[36] Namiki, S., Ishidoya, S., Ito, A., Kawamura, S., Tochigi, T., Saito, S. and Arai, Y. (2009) Quality of Life after Radical Prostatectomy in Japanese Men: A 5-Year Follow Up Study. International Journal of Urology, 16, 75-81. http://dx.doi.org/10.1111/j.1442-2042.2008.02197.x

[37] Fowler Jr., F.J., Barry, M.J., Lu-Yao, G., Wasson, J., Roman, A. and Wennberg, J. (1995) Effect of Radical Prostatectomy for Prostate Cancer on Patient Quality of Life: Results from a Medicare Survey. Urology, 45, 1007-1013. http://dx.doi.org/10.1016/S0090-4295(99)80122-8

[38] Braslis, K.G., Santa-Cruz, C., Brickman, A.L. and Soloway, M.S. (1995) Quality of Life 12 Months after Radical Prostatectomy. British Journal of Urology, 75, 48-53. http://dx.doi.org/10.1111/j.1464-410X.1995.tb07231.x

[39] Korfage, I.J., Essink-Bot, M.L., Borsboom, G.J., Madalinska, J.B., Kirkels, W.J., Habbema, J.D., Schröder, F.H. and de Koning, H.J. (2005) Five-Year Follow-Up of Health-Related Quality of Life after Primary Treatment of Localized Prostate Cancer. International Journal of Cancer, 16, 291-296. http://dx.doi.org/10.1002/ijc.21043

[40] Slova, D. and Lepor, H. (2007) The Short-Term and Long-Term Effects of Radical Prostatectomy on Lower Urinary Tract Symptoms. Journal of Urology, 178, 2397-400. http://dx.doi.org/10.1016/j.juro.2007.08.004

[41] WHOQOL Group (1993) Study Protocol for the World Health Organization Project to Develop a Quality of Life Assessment Instrument (WHOQOL). Quality of Life Research, 2, 153-159.

[42] Arai, Y., Okubo, K., Aoki, Y., Maekawa, S., Okada, T., Maeda, H., Ogawa, S. and, Kato, T. (1999) Patient-Reported Quality of Life after Radical Prostatectomy for Prostate Cancer. International Journal of Urology, 6, 78-86. http://dx.doi.org/10.1046/j.1442-2042.1999.00629.x

[43] Martin, A.D., Nakamura, L.Y., Nunez, R.N., Wolter, C.E., Humphreys, M.R. and Castle, P. (2011) Incontinence after Radical Prostatectomy: A Patient Centered Analysis and Implications for Preoperative Counseling. Journal of Urology, 186, 204-208. http://dx.doi.org/10.1016/j.juro.2011.02.2698

[44] Hoffman, R.H., Hunt, W.C. and Stephenson RA. (2003) Patient Satisfaction with Treatment Decisions for Clinically Localized Prostate Carcinoma. Results from the Prostate Cancer Outcomes Study. Cancer, 97, 1653-1662. http://dx.doi.org/10.1002/cncr.11233

[45] Haltbakk, J., Hanestad, B.R. and Hunskaar, S. (2005) How Important Are Men's Lower Urinary Tract Symptoms (LUTS) and Their Impact on the Quality of Life (QOL)? Quality of Life Research, 4, 1733-1741. http://dx.doi.org/10.1007/s11136-005-3232-x 
[46] Hu, J.C., Elkin, E.P., Pasta, D.J., Lubeck, D.P., Kattan, M.W., Carroll, P.R. and Litwin, M.S. (2004) Predicting Quality of Life after Radical Prostatectomy: Results from CaPSURE. Journal of Urology, 171, 703-707. http://dx.doi.org/10.1097/01.ju.0000107964.61300.f6

[47] Aaronson, N.K. (1990) Quality of Life Research in Cancer Clinical Trials: A Need for Common Rules and Language. Oncology, 4, 59-66. http://dx.doi.org/10.1016/i.ijrobp.2006.10.011

[48] Buron, C., Le Vu, B., Cosset, J.M., Pommier, P., Peiffert, D., Delannes, M., Flam, T., Guerif, S., Salem, N., Chauveinc, L. and Livartowski, A. (2007) Brachytherapy versus Prostatectomy in Localized Prostate Cancer: Results of a French Multicenter Prospective Medico-Economic Study. International Journal of Radiation Oncology Biology Physics, 67, 812-822. http://dx.doi.org/10.1016/j.ijrobp.2006.10.011

[49] Ebrahim, S. (1995) Clinical and Public Health Perspectives and Applications of Health-Related Quality of Life Measurement. Social Science \& Medicine, 41, 1383-1394. http://dx.doi.org/10.1016/0277-9536(95)00116-O

[50] Lubeck, D.P., Litwin, M.S., Henning, J.M., Stoddard, M.L., Flanders, S.C. and Carroll, P.R. (1999) Changes in HealthRelated Quality of Life in the First Year after Treatment for Prostate Cancer: Results from CaPSURE. Urology, 53, 180-186. http://dx.doi.org/10.1016/S0090-4295(98)00408-7

[51] Maguire, P. and Selby, P. (1989) Assessing Quality of Life in Cancer Patients. British Journal of Cancer, 60, 437-440. http://dx.doi.org/10.1038/bjc.1989.301

[52] Namiki, S., Satoh, T., Baba, S., Ishiyama, H., Hayakawa, K., Saito, S., Arai, Y. (2006) Quality of Life after Brachytherapy or Radical Prostatectomy for Localized Prostate Cancer: A Prospective Longitudinal Study. Urology, 68, 1230 1236. http://dx.doi.org/10.1016/j.urology.2006.08.1093

[53] McHorney, C.A., Ware Jr., J.E. and Raczek, A.E. (1993) The MOS 36-Item Short-Form Health Survey (SF-36): II. Psychometric and Clinical Tests of Validity in Measuring Physical and Mental Health Constructs. Medical Care, 31, 247-263. http://dx.doi.org/10.1097/00005650-199303000-00006 